\title{
A retrospective analysis of the postoperative use of loteprednol etabonate gel $0.5 \%$ following laser- assisted in situ keratomileusis or photorefractive keratectomy surgery
}

\author{
This article was published in the following Dove Press journal: \\ Clinical Ophthalmology \\ 6 November 2015 \\ Number of times this article has been viewed
}

\author{
Clifford L Salinger ${ }^{1}$ \\ Michael Gordon ${ }^{2}$ \\ Mitchell A Jackson ${ }^{3}$ \\ Theodore Perl ${ }^{4}$ \\ Eric Donnenfeld ${ }^{5}$ \\ 'VIP Laser Eye Center, Palm Beach \\ Gardens, FL, ${ }^{2}$ Gordon Weiss Schanzlin \\ Vision Institute, San Diego, CA, \\ ${ }^{3}$ Jacksoneye, Lake Villa, IL, ${ }^{4}$ Corneal \\ Associates of New Jersey, Fairfield, \\ $\mathrm{NJ},{ }^{5}$ Ophthalmic Consultants of Long \\ Island, Garden City, NY, USA
}

\begin{abstract}
Background: While loteprednol etabonate ophthalmic gel $0.5 \%$ (LE gel) is approved for treatment of postoperative ocular inflammation and pain, there have been no reported studies in patients undergoing laser-assisted in situ keratomileusis (LASIK) or photorefractive keratectomy (PRK).
\end{abstract}

Methods: This was a retrospective chart review conducted at five refractive surgical centers in the USA. Data were collected from primary LASIK or PRK surgery cases in which LE gel was used postoperatively as the clinician's routine standard of care and in which patients were followed-up for up to 6 months. Data extracted from charts included patient demographics, surgical details, LE gel dosing regimen, pre- and postsurgical refractive characteristics, intraocular pressure (IOP) measurements, and visual acuity. Primary outcomes included postoperative IOP elevations, adverse events, and early discontinuations.

Results: Data were collected on 189 LASIK eyes (96 patients) and 209 PRK eyes (108 patients). Mean (standard deviation [SD]) years of age at surgery was 36.0 (11.7) and 33.9 (11.3) in LASIK and PRK patients. LE gel was prescribed most often four times daily during the first postoperative week, regardless of procedure; the most common treatment duration was 7-14 days in LASIK and $\geq 30$ days in PRK patients. No unusual corneal findings or healing abnormalities were reported. Mean postoperative uncorrected distance visual acuity was 20/24 in LASIK and 20/30 in PRK eyes. Mild/trace corneal haze was reported in $20 \%$ of PRK patients; two PRK patients with moderate/severe corneal haze were switched to another corticosteroid. Mean postoperative IOP did not increase over time in either LASIK or PRK eyes ( $P \geq 0.331)$; clinically significant elevations from baseline in IOP ( $\geq 10 \mathrm{mmHg}$ ) were noted in only three eyes of two PRK patients.

Conclusion: LE gel appears to have a high level of safety and tolerability when used for the management of postoperative pain and inflammation following LASIK and PRK surgery.

Keywords: loteprednol etabonate, intraocular pressure, chart review, safety, postoperative pain and inflammation

\section{Introduction}

Refractive surgeries utilizing excimer laser technology are widely used to alter corneal curvature and correct vision. ${ }^{1}$ Photorefractive keratectomy (PRK) and laserassisted in situ keratomileusis (LASIK), in particular, have a long track record of safety and efficacy. They have each been performed for more than 20 years and have different advantages and disadvantages. Surface ablation methods such as PRK allow for greater preservation of residual posterior stromal tissue and avoid complications related to flap creation and healing. PRK may also have a lower risk
Correspondence: Clifford L Salinger VIP Laser Eye Center, I I020 RCA Center Drive, Suite 200I, Palm Beach Gardens, FL 33410, USA

Tel +I 5616247878

Email drsalinger@comcast.net 
of keratectasia. ${ }^{2,3}$ However, compared with LASIK, PRK typically has a lengthier and less comfortable recovery process. ${ }^{1,4}$ Corneal haze formation and infectious keratitis are other possible complications of PRK that can potentially be vision-threatening. ${ }^{5-10}$

Topical ophthalmic corticosteroids are often utilized for the management of PRK and LASIK patients to minimize postoperative pain and inflammation. ${ }^{1}$ In PRK, ophthalmic corticosteroids may have an added benefit of minimizing haze formation, a phenomenon that has been demonstrated in clinical studies, ${ }^{11,12}$ although there exist contrary data suggesting no significant benefit in this regard. ${ }^{13,14}$ Despite the postoperative benefits of ophthalmic corticosteroids, potential risks associated with their use include intraocular pressure (IOP) elevation, formation of cataracts, infection, and delayed corneal epithelial healing. ${ }^{15}$

Loteprednol etabonate (LE) is a C-20 ester corticosteroid designed at a molecular level to have an improved therapeutic index over traditional corticosteroids. Due to the replacement of the C-20 ketone group present in all other corticosteroids with a chloromethyl ester group, LE molecules that are not bound to glucocorticoid receptors are quickly de-esterified into inactive metabolites, reducing the potential for unwanted side effects. ${ }^{16-18}$ The safety and efficacy of LE suspension and ointment formulations have been studied in patients undergoing ocular procedures including cataract surgery, ${ }^{19-21}$ LASIK, ${ }^{22-25}$ and PRK. ${ }^{26,27}$ These and other investigations have confirmed a minimal risk of IOP elevation in patients treated with LE, including individuals who are known steroid responders. ${ }^{28,29}$

A non-settling gel formulation of LE became available in 2013, which provides consistent, uniform dosing while eliminating the need for shaking prior to administration. ${ }^{30}$ The gel formulation is thought to provide increased contact time with the ocular surface..$^{30}$ In addition, the gel formulation has a $\mathrm{pH}$ more similar to that of human tears and a $70 \%$ lower preservative concentration than the suspension formulation. ${ }^{30}$ The safety and efficacy of LE ophthalmic gel $0.5 \%$ (LE gel) were evaluated in two Phase III randomized vehiclecontrolled clinical trials in subjects with postoperative pain and inflammation following cataract surgery. ${ }^{31,32}$ In these studies, only $0.5 \%$ of subjects experienced transient, clinically significant IOP elevations ( $\geq 10 \mathrm{mmHg}$ ) over baseline during the 2-week treatment period. While LE gel is approved for the treatment of inflammation and pain following ocular surgery, there have been no published studies evaluating the safety of this new formulation in patients undergoing either LASIK or PRK. The purpose of this retrospective study was to assess prescribing behaviors and safety outcomes associated with the use of LE gel for these procedures.

\section{Patients and methods Study design}

This was a medical chart review study conducted at five US refractive surgery sites. Retrospective data were collected on eligible patients at each study site, reflecting the routine care and follow-up of patients who were prescribed LE gel $0.5 \%$ in association with LASIK or PRK surgery. The study protocol was approved by the Chesapeake Institutional Review Board (Columbia, MD, USA), which granted a waiver for informed consent given the retrospective nature of the data collection. All subject data were de-identified and kept confidential in accordance with the International Conference on Harmonization Guidelines for Good Clinical Practice..$^{33}$

Patients aged 18 years or older who had undergone LASIK or PRK surgery prior to March, 2014, and whose perioperative management included LE gel were eligible for inclusion. The surgical procedure must have been the primary surgery, not an enhancement or reoperation. The eligibility cutoff date ensured a minimum time interval of 6 months between surgery and data collection. Reasons for exclusion included use of LE gel for surgical procedures other than LASIK or PRK, and use of ocular steroids other than LE gel for the current LASIK/PRK procedure. Charts of all cases meeting eligibility criteria were identified by personnel at each study site. Information was hand-recorded onto case report forms on-site and then entered electronically into a centralized database.

Data extracted from the medical charts included the following: patient demographics; surgical details; LE gel dosing, frequency, and duration; pre- and postsurgical ocular characteristics including sphere, cylinder, axis, and uncorrected visual acuity (UCVA); pre- and postsurgical IOP measurements; concomitant medications; adverse events (AEs); and early discontinuations. The primary outcomes evaluated included IOP change from baseline, other AEs, any abnormal corneal findings, and early treatment discontinuations.

\section{Data analysis}

A minimum sample size of 150 LASIK eyes and 150 PRK eyes was planned. Eyes from patients undergoing bilateral LASIK or PRK were considered separately. IOP findings were evaluated as pre- and postoperative means for the LASIK and PRK groups, separately. A one-way analysis of variance (ANOVA) was used to evaluate any changes in mean IOP by postoperative period $(0-30,31-60,61-90$, and 
$>90$ days). The ANOVA was performed using Statistix 10 (Analytical Software, Tallahassee, FL, USA), and a $P$-value $<0.05$ was considered significant. Observed increases of IOP $\geq 10 \mathrm{mmHg}$ over baseline, considered clinically significant, and observed increases of IOP $\geq 5 \mathrm{mmHg}$ over baseline, considered clinically relevant, were summarized categorically. All other outcomes were analyzed descriptively.

\section{Results}

Data were collected on 189 LASIK eyes (96 patients) and 209 PRK eyes (108 patients) from five clinical sites. The LASIK group had a higher female representation and was slightly older on average compared with the PRK group (Table 1). Mean ( \pm standard deviation [SD]) baseline IOP was 15.5 (2.2) $\mathrm{mmHg}$ in LASIK eyes and 14.6 (2.7) $\mathrm{mmHg}$ in PRK eyes. All IOP measurements were performed using applanation tonometry. Other preoperative ocular measurements and UCVA findings are presented in Table 2. Baseline UCVA appeared slightly worse in the PRK eyes compared with the LASIK eyes.

In the LASIK group, 81 (42.9\%) of flaps were created with a femtosecond laser, and $106(56.1 \%)$ with a microkeratome; flap technique was not recorded for two (1.1\%) eyes. Mean (SD) calculated/intended flap thickness in the LASIK group was $112.5(44.5) \mu \mathrm{m}$. Mean (SD) ablation depth was $59.1(30.5) \mu \mathrm{m}$ in the LASIK group and 65.8 (32.7) $\mu \mathrm{m}$ in the PRK group. Per PRK standard operating procedures, all surgeons applied mitomycin C $0.2 \%-0.25 \%$ either as a drop to the ablation area or a soaked cellulose sponge applied to the central corneal surface, either immediately following ablation or at the conclusion of the procedure for a minimum of 10 seconds to a maximum of 25 seconds depending on surgeon preference.

Table I Demographic characteristics and preoperative IOP of surgical groups

\begin{tabular}{lll}
\hline & LASIK & PRK \\
\hline $\begin{array}{l}\text { Patients (n) } \\
\text { Eyes }(\mathrm{n})\end{array}$ & 96 & 108 \\
$\begin{array}{l}\text { Sex, } \mathrm{n}(\%) \\
\quad \text { Male }\end{array}$ & 189 & 209 \\
$\quad$ Female & $39(40.6)$ & $60(55.6)$ \\
Age (years) & $57(59.4)$ & $48(44.4)$ \\
$\quad$ Mean (SD) & & \\
$\quad$ Range & $36.0(\mathrm{II} .7)$ & $33.9(\mathrm{II} .3)$ \\
Preoperative IOP (mmHg) & $18-63$ & $18-68$ \\
$\quad$ Mean (SD) & & $14.6(2.7)$ \\
$\quad$ Range & $15.5(2.2)$ & $7-26$ \\
\hline
\end{tabular}

Abbreviations: IOP, intraocular pressure; LASIK, laser-assisted in situ keratomileusis; PRK, photorefractive keratectomy; SD, standard deviation.

\section{Treatment regimens}

Preoperative application of LE gel was noted in ten $(5.3 \%)$ LASIK eyes and 24 (11.5\%) PRK eyes. Administration of LE gel in postoperative recovery and throughout the balance of the day of surgery was more commonly reported with LASIK than PRK (Table 3). There were no instances noted of LE gel being applied intraoperatively to the stromal bed or directly to the flap following closure during LASIK procedures, or before or immediately following placement of a bandage contact lens in PRK procedures.

During the first postoperative week, LE gel was prescribed most frequently as one drop QID (four times daily), regardless of type of surgery (Figure 1). The most common duration of postoperative LE gel therapy was 7-14 days for LASIK cases and 30 days or longer in PRK cases (Figure 2). Duration of LE gel therapy was 60 days or shorter in all LASIK cases. Among PRK cases, more than one-third (34.9\%) of eyes were treated with LE gel longer than 60 days, and $26.9 \%$ of eyes were treated with LE gel for more than 90 days. Standard operating procedures at each study site typically dictated a tapering of LE gel dosing frequency beyond the first week of treatment.

Postoperatively, the most frequently reported concomitant antibacterials in the LASIK group were moxifloxacin $0.5 \%$ (53.1\% of patients) and besifloxacin $0.6 \%$ (39.6\%), and in the PRK group, moxifloxacin $0.5 \%(56.5 \%)$ and gatifloxacin $0.5 \%(31.5 \%)$. The most common non-corticosteroid antiinflammatory agents used postoperatively were cyclosporine A $0.05 \%$ (42.7\%) post-LASIK and bromfenac $0.09 \%$ or $0.07 \%$ (36.1\%) post-PRK. All patients were prescribed lubricants/artificial tear products postoperatively.

\section{Surgical outcomes and safety findings}

Table 2 summarizes pre- and postoperative outcomes. Mean (SD) postoperative sphere and cylinder were $-0.04(0.49)$ and $-0.28(0.45)$ diopters in LASIK eyes and $-0.09(0.77)$ and $-0.50(0.45)$ diopters in PRK eyes. Mean postoperative UCVA was 20/24 in LASIK eyes and 20/30 in PRK eyes.

There were no reports of abnormal corneal morphology, corneal edema, wound healing/integrity, infection, or reports of corneal infiltrates or any unexpected findings noted in the charts including flap dislocation (LASIK). Among PRK cases, corneal haze was noted in $40(19.1 \%)$ eyes in $22(20 \%)$ patients postoperatively. These were all characterized as "mild" or "trace" (or simply recorded as "yes") with the following exceptions (three eyes in two patients): corneal haze was characterized as "severe" in both eyes of a 21-year-old female patient treated with LE gel, one drop QID, and which 
Table 2 Pre- and postoperative* ocular characteristics

\begin{tabular}{|c|c|c|c|c|}
\hline \multirow{2}{*}{$\begin{array}{l}\text { Ocular } \\
\text { characteristics }\end{array}$} & \multicolumn{2}{|l|}{ LASIK } & \multicolumn{2}{|l|}{ PRK } \\
\hline & Pre-op ( $n=\mid 89$ eyes) & Post-op ( $n=89$ eyes) & Pre-op (n=209 eyes) & Post-op ( $n=99$ eyes) \\
\hline UCVA (20/\#) mean (SD) & $236.2(152.2)$ & $24.4(16.2)$ & $251.5(166.2)$ & $30.4(43.8)$ \\
\hline \multicolumn{5}{|l|}{ Sphere (D) } \\
\hline Mean (SD) & $-2.94(2.65)$ & $-0.04(0.49)$ & $-2.76(3.15)$ & $-0.09(0.77)$ \\
\hline Median (range) & $-2.75(-9.75$ to 3.50$)$ & $0(-1.00$ to 1.50$)$ & $-3.00(-9.99$ to 9.00$)$ & $0(-0.09$ to 0.77$)$ \\
\hline \multicolumn{5}{|l|}{ Cylinder (D) } \\
\hline Mean (SD) & $-0.83(1.21)$ & $-0.28(0.45)$ & $-1.15(1.13)$ & $-0.50(0.45)$ \\
\hline Median (range) & $-0.50(-8.00$ to 0.00$)$ & $0(-2.50$ to 0.00$)$ & $-0.75(-6.00$ to 0.00$)$ & $-0.50(-1.75$ to 0.00$)$ \\
\hline \multicolumn{5}{|l|}{ Axis, $n(\%)$} \\
\hline With the rule & $104(55.0)$ & $62(69.7)$ & $109(52.2)$ & $73(76.0)$ \\
\hline Against the rule & $43(22.8)$ & $15(16.9)$ & $52(24.9)$ & $7(7.3)$ \\
\hline Oblique & $4 I(2 I .7)$ & $12(13.5)$ & $47(22.5)$ & $16(16.7)$ \\
\hline \multicolumn{5}{|l|}{ Pachymetry $(\mu \mathrm{m})$} \\
\hline Mean (SD) & $549.4(33.6)$ & NA & $525.6(35.7)$ & NA \\
\hline Median (range) & $549(468-633)$ & NA & $528(434-616)$ & NA \\
\hline
\end{tabular}

Notes: *Latest recorded value noted during follow-up in patient chart. "Represents the denominator of the UCVA measurements.

Abbreviations: D, diopters; LASIK, laser-assisted in situ keratomileusis; NA, not available; post-op, postoperative; pre-op, preoperative; PRK, photorefractive keratectomy; UCVA, uncorrected visual acuity; SD, standard deviation.

led to LE gel treatment discontinuation. Briefly, the procedure involved chemical alcohol epithelial removal with a resulting epithelial wound size of $8.5 \mathrm{~mm}$. No haze was reported for this patient on postoperative day 4 when the bandage contact lens (BCL) was removed. However, trace corneal haze was reported in both eyes on postoperative day 13, progressing to moderate corneal haze on day 48 , and severe corneal haze on day 83 and day 118 . On the day 118 visit, therapy was switched from LE gel to prednisolone 1\% one drop QID. The haze failed to resolve and additional treatment was planned including topical mitomycin $\mathrm{C}$. The second case, also performed using chemical alcohol epithelial removal, occurred in a 32-year-old male patient treated postoperatively with LE gel, one drop QID, who was first noted to have trace corneal haze in one eye on postoperative day 20 and moderate corneal haze on day 41 . Topical steroid therapy was switched to difluprednate, but no further follow-up was available. Both these patients (as well as all other PRK cases) were treated with mitomycin $\mathrm{C}$ during the primary keratorefractive procedure. No other patients were noted to have stopped LE gel prematurely or switched to a different topical corticosteroid.
Figure 3 shows the mean $( \pm$ SD) preoperative and postoperative IOP over time in LASIK and PRK eyes. Postoperative IOP measurements ranged from 9 to $21 \mathrm{mmHg}$ in LASIK eyes and from 7 to $29 \mathrm{mmHg}$ in PRK eyes. Postoperative mean IOP did not increase over time in either LASIK eyes $(F=1.17, P=0.3311)$ or PRK eyes $(F=0.98, P=0.407)$. As indicated earlier, LASIK patients received postoperative LE gel therapy most often for 7-14 days, whereas PRK patients received postoperative LE gel therapy most often for 31-60 days. Mean (SD) IOP over these time frames was 14.68 (2.28) $\mathrm{mmHg}$ and 15.60 (2.91) $\mathrm{mmHg}$ for LASIK and PRK patients, respectively, ranging from 9 to $21 \mathrm{mmHg}$ in LASIK eyes and 10 to $23 \mathrm{mmHg}$ in PRK eyes.

Table 4 shows IOP elevations $\geq 5 \mathrm{mmHg}$ above baseline and $\geq 10 \mathrm{mmHg}$ above baseline. Clinically significant elevations from baseline in IOP ( $\geq 10 \mathrm{mmHg}$ ) were noted in only two patients (three eyes), both in the PRK group. A 28-yearold male patient (baseline IOPs, 17 and $19 \mathrm{mmHg}$ ) had an IOP measurement of $29 \mathrm{mmHg}$ in both eyes on postoperative day 18 while using LE gel one drop QID. LE gel dosage was decreased to one drop BID, and IOP measured 3 days later

Table 3 LE gel administration on day of surgery

\begin{tabular}{|c|c|c|}
\hline & LASIK ( $n=\mid 89$ eyes) & PRK ( $n=209$ eyes) \\
\hline Preoperative application*, n (\%) & $10(5.3)$ & $24(11.5)$ \\
\hline $\begin{array}{l}\text { Application to the stromal bed or to the flap following closure (LASIK) or before or immediately } \\
\text { following bandage contact lens placement (PRK), } n(\%)\end{array}$ & 0 & 0 \\
\hline In postoperative recovery, n (\%) & $166(87.8)$ & $55(26.3)$ \\
\hline Throughout the balance of the operative day, $\mathrm{n}(\%)$ & $182(96.3)$ & $89(42.6)$ \\
\hline
\end{tabular}

Note: *Preoperative medication use was not specified in all patient charts but was recorded where available.

Abbreviations: LASIK, laser-assisted in situ keratomileusis; LE gel, loteprednol etabonate ophthalmic gel 0.5\%; PRK, photorefractive keratectomy. 


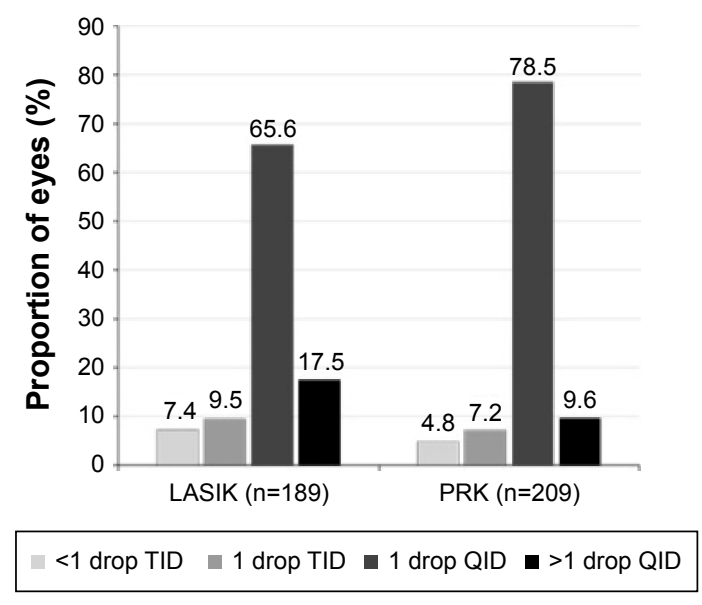

Figure I LE gel dosing frequency during first postoperative week. Abbreviations: LASIK, laser-assisted in situ keratomileusis; LE gel, loteprednol etabonate ophthalmic gel $0.5 \%$; QID, four times daily; PRK, photorefractive keratectomy; TID, three times daily.

was $18 \mathrm{mmHg}$ in both eyes, and $19 \mathrm{mmHg}$ in both eyes after another 14 days. A 20-year-old female PRK patient (baseline IOPs, $14 \mathrm{mmHg}$ OD, $13 \mathrm{mmHg}$ OS) was prescribed LE gel one drop QID. On postoperative day 41, IOP was $19 \mathrm{mmHg}$ OD and $23 \mathrm{mmHg}$ OS. LE gel dosage was decreased to one drop three times daily. No further IOP measurements or other follow-up were available on this patient. Less significant/ marked IOP elevations $\geq 5 \mathrm{mmHg}$ were noted in one $(0.6 \%)$ LASIK eye in the first postoperative month and one $(4.2 \%)$ LASIK eye with follow-up $>90$ days (noted during a separate course of LE gel for dry eye approximately 6 months

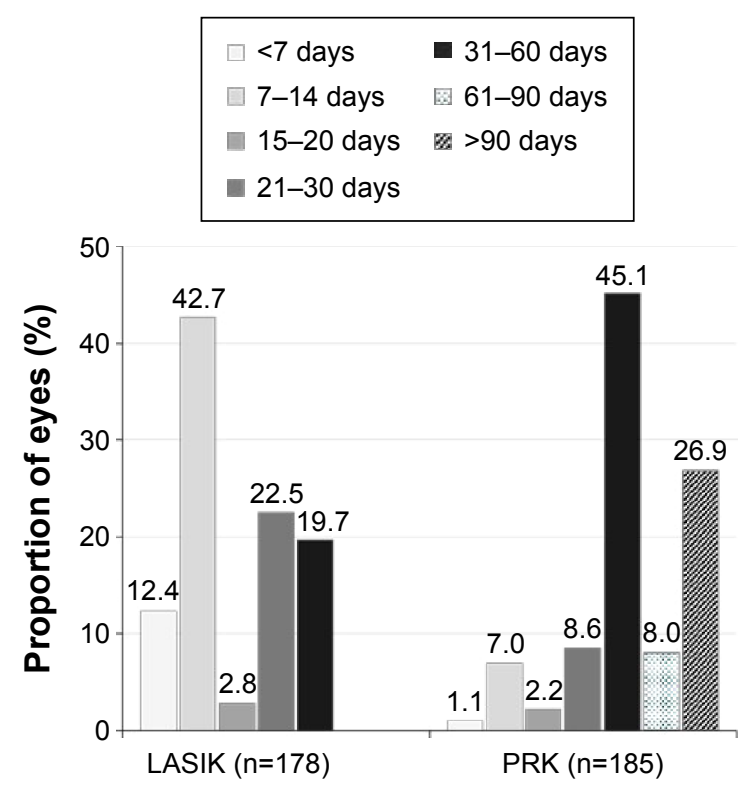

Figure 2 Postoperative duration of LE gel treatment.

Abbreviations: LASIK, laser-assisted in situ keratomileusis; LE gel, loteprednol etabonate ophthalmic gel $0.5 \%$; PRK, photorefractive keratectomy.
post-LASIK; see footnote in Table 4). In contrast, among PRK eyes, IOP elevations of $\geq 5 \mathrm{mmHg}$ occurred in 12 (11.5\%) eyes within the first postoperative month, 12 (16.7\%) eyes during the second postoperative month, six (11.1\%) eyes with follow-up during the third postoperative month, and two $(3.3 \%)$ eyes with follow-up extending longer than 90 days.

\section{Discussion}

The data gathered in this review of real-world use of LE gel in nearly 400 post-LASIK and post-PRK eyes indicate a high level of safety with this topical corticosteroid in both surgical procedures. There were no unexpected findings, and no patient was noted to have discontinued therapy prematurely with the exception of two PRK patients with corneal haze who both discontinued LE gel and were switched, one to prednisolone with no significant reduction in haze, and the other to difluprednate with no further follow-up available. Consistent with numerous prior studies with LE gel and other LE $0.5 \%$ formulations, ${ }^{19-27,31}$ clinically significant IOP elevations ( $\geq 10 \mathrm{mmHg}$ ) were rare in this chart review and noted in only two $(0.5 \%)$ patients (three eyes). In one patient for which sufficient follow-up information was available, reduction in LE gel administration frequency corresponded with a return of IOP to baseline levels. As might be expected, smaller IOP elevations ( $\geq 5 \mathrm{mmHg}$ ) were more frequent, and most often observed in PRK eyes, but still only noted in a small percentage of eyes overall. Notably, in PRK patients, considered at greater risk of IOP elevation, there were no elevations $\geq 10 \mathrm{mmHg}$ reported for any eyes treated with LE gel beyond 60 days. In addition, mean postoperative IOP did not demonstrate any increase over the follow-up time frame which exceeded 60 days in a little more than one-third and 90 days in a little more than one-fourth of PRK eyes.

The dosing regimens of LE gel observed in this study followed expected patterns. Preoperatively, LE gel was administered in a small number of LASIK and PRK cases, and there were no instances of intraoperative administration. Ocular corticosteroids are recommended postoperatively for a short-time post-LASIK and for periods ranging from weeks to months following PRK. ${ }^{1}$ In this study, almost all LASIK patients and nearly half of PRK patients began using postoperative LE gel on the same day as the surgery following completion of the procedure. The most common duration of LE gel treatment following LASIK was 7-14 days, with slightly less than $20 \%$ treated more than 30 days postoperatively. In contrast, $80 \%$ of PRK eyes were treated with LE gel for more than 30 days postoperatively, with slightly more than one-third treated for more than 60 days, and slightly more than 


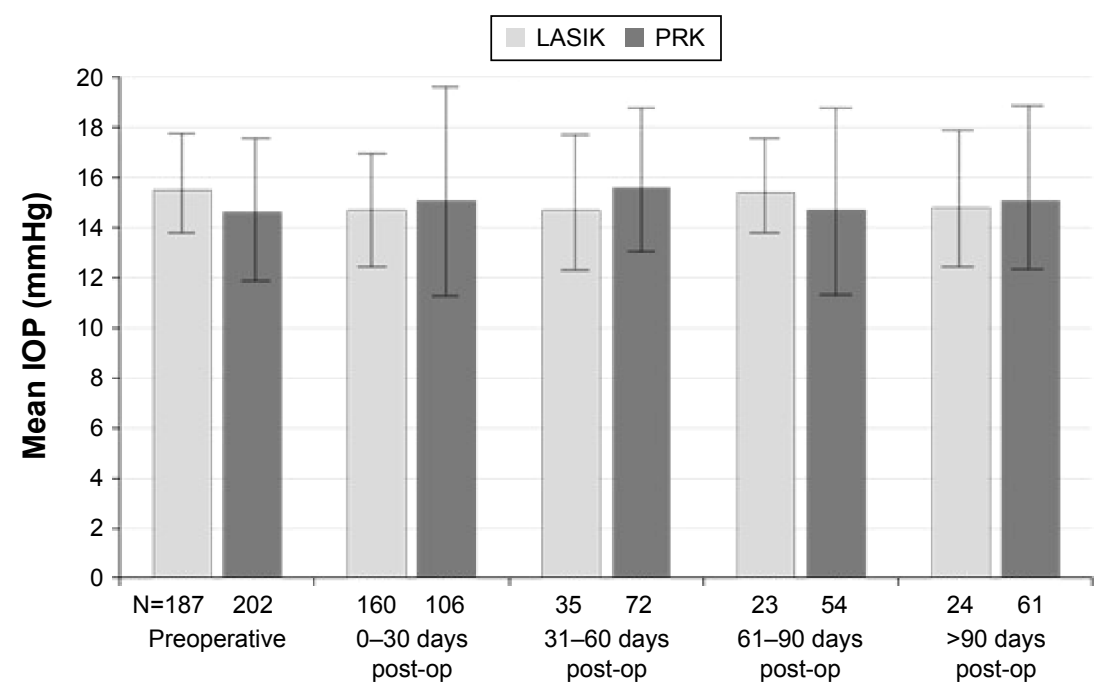

Timing of IOP measurement

Figure 3 Mean (SD) IOP measurements over time.

Notes: Bars represent all available IOP measurements during the given time frames. $\mathrm{N}$ values represent the number of eyes with IOP measurements available during each follow-up time frame. If more than one IOP was recorded for a given eye within a time frame, the highest value was used.

Abbreviations: IOP, intraocular pressure; LASIK, laser-assisted in situ keratomileusis; post-op, postoperative; PRK, photorefractive keratectomy; SD, standard deviation.

one-fourth treated for more than 90 days. It should be noted that treatment duration was sometimes difficult to establish from patient charts. In some instances, standing orders were evident in the patient charts, outlining the planned course of treatment including LE gel dosing and planned duration, but there was no further documentation of LE gel usage within follow-up visit notes. In the absence of specific mention of treatment discontinuation, length of therapy was assumed to be according to respective site protocol.

Topical corticosteroids are highly valued in ophthalmology for their potent anti-inflammatory activity and utility in

Table 4 IOP elevations, categorical changes from baseline

\begin{tabular}{|c|c|c|c|}
\hline \multirow{2}{*}{$\begin{array}{l}\text { Postoperative } \\
\text { time frame }\end{array}$} & \multirow{2}{*}{$\begin{array}{l}\text { Eyes, } \\
n\end{array}$} & \multicolumn{2}{|l|}{ IOP elevation } \\
\hline & & $\geq 10 \mathrm{mmHg}, \mathrm{n}(\%)$ & $\geq 5 \mathrm{mmHg}, \mathrm{n}(\%)$ \\
\hline \multicolumn{4}{|l|}{ PRK, days } \\
\hline $0-30$ & 104 & $2(1.9)$ & $12(\mathrm{II} .5)$ \\
\hline $31-60$ & 72 & I (I.4) & $12(16.7)$ \\
\hline $61-90$ & 54 & $0(0.0)$ & $6(11.1)$ \\
\hline$>90$ & 61 & $0(0.0)$ & $2(3.3)$ \\
\hline \multicolumn{4}{|l|}{ LASIK, days } \\
\hline $0-30$ & 158 & $0(0.0)$ & I $(0.6)$ \\
\hline $31-60$ & 35 & $0(0.0)$ & $0(0.0)$ \\
\hline $61-90$ & 23 & $0(0.0)$ & $0(0.0)$ \\
\hline$>90$ & 24 & $0(0.0)$ & I $(4.2)^{*}$ \\
\hline
\end{tabular}

Notes: *This subject with a history of dry eye used LE gel for 36 days prior and 25 days following LASIK without notable IOP elevation relative to baseline; 5 months later, the subject underwent a 30-day course of LE gel for dry eye, during which time, IOP in one eye was noted to be $6 \mathrm{mmHg}$ higher than pre-LASIK baseline. Follow-up 2 months later revealed an IOP below the baseline value in this eye. Abbreviations: LASIK, laser-assisted in situ keratomileusis; LE gel, loteprednol etabonate ophthalmic gel $0.5 \%$; IOP, intraocular pressure, PRK, photorefractive keratectomy. preventing certain postoperative complications, and have become a routine component of postsurgical management. However, corticosteroid class side effects such as IOP elevation, cataract formation, and delayed healing can complicate therapy and warrant a careful approach and vigilant follow-up when corticosteroids are administered directly onto the eye. The mechanism of corticosteroid-induced IOP elevation is theorized to involve glucocorticoid receptor-mediated changes in regulation of myocilin gene expression with a resulting decrease in outflow of aqueous humor secondary to changes in the trabecular meshwork. ${ }^{34} \mathrm{LE}$ has the ability to bind to the glucocorticoid receptor with greater affinity than dexamethasone and elicits potent and efficacious antiinflammatory activity. ${ }^{17,18}$ However, due to the replacement of the C-20 ketone with a chloromethyl ester, unbound LE is rapidly metabolized into inactive metabolites thus limiting the potential to mediate unwanted side effects. In fact, clinical studies to date of this unique C-20 ester corticosteroid have reported consistently low rates of IOP elevation, comparable to vehicle and lower in comparison with other topical corticosteroids, ${ }^{33}$ including dexamethasone, ${ }^{25,27,35-37}$ prednisolone, ${ }^{20,28,29,38,39}$ and fluoromethalone. ${ }^{23,24,40}$ The IOP findings from this chart review specific to the use of LE gel in refractive surgery extend the available safety data for LE gel beyond the postcataract surgery setting, and are consistent with findings from studies evaluating other LE formulations in refractive surgery. Thus, Zhang et $\mathrm{a}^{22}$ recently described a chart review of 1,552 eyes that underwent excimer laser corneal refractive surgery managed postoperatively with LE 
suspension for 4 weeks (tapered regimen). Elevations in IOP, defined in this study as any increase in IOP over baseline ("low reaction", $<5 \mathrm{mmHg}$ increase; "moderate reaction", 5-15 mmHg increase; and "strong reaction", $>15 \mathrm{mmHg}$ increase), were noted in 47 (3.0\%) eyes occurring most often after 2 weeks of treatment. Four $(0.3 \%)$ eyes were noted to have an IOP $>15 \mathrm{mmHg}$ over baseline. All IOP changes were reversible upon discontinuation of LE or treatment with $0.1 \%$ timolol hydrochloride. Similarly, Mifflin et $\mathrm{al}^{26}$ reported results from a chart review of 579 eyes undergoing PRK treated postoperatively with either fluorometholone $0.1 \%$ (FML) or LE suspension, and reported clinically significant IOP elevations, defined as IOP elevations to $>25 \mathrm{mmHg}$ or $>10 \mathrm{mmHg}$ over baseline, in three (1.1\%) FML eyes and four $(1.3 \%)$ LE eyes over the 3 months follow-up. Mean IOP and/or elevations in IOP were also minimal in three prospective, comparative clinical trials of LE suspension for control of inflammation and pain following refractive surgery: $\mathrm{Li}$ et $\mathrm{al}^{23}$ reported mean IOP was reduced from preoperative IOP in 160 eyes treated with LE suspension or FML following LASIK surgery and significantly lower in the LE-treated eyes compared with the FML-treated eyes $(P<0.05)$. Gao et $\mathrm{al}^{24}$ reported fewer IOP elevations in post-LASEK surgery eyes treated with LE vs those treated with FML (1.5\% vs $6 \% ; P<0.05)$. Patients $(\mathrm{n}=400)$ in that study received 1 -week treatment with dexamethasone $0.1 \%$ /tobramycin $0.03 \%$ (dexamethasone/T) and fibroblast growth factor eye drops prior to being switched to either LE suspension or FML. Finally, Wu et al ${ }^{25}$ compared the efficacy of 1-week treatment with $\mathrm{LE}$ that of dexamethasone/ $\mathrm{T}$ in controlling postoperative inflammation in 224 post-LASIK eyes. An increase in mean IOP was noted at 1 week for dexamethasone/T-treated subjects compared with baseline $(P<0.05)$ but not for LEtreated subjects.

The newer gel formulation of LE offers some benefits relative to the ointment and suspension formulations. The gel formulation has $70 \%$ less benzalkonium chloride preservative and a more physiologic $\mathrm{pH}$ when compared with the suspension formulation. The gel also contains two additional demulcents that act as moisturizing agents. LE suspension requires vigorous shaking prior to administration in order to ensure uniform distribution of drug and consistent dosing. LE gel is a non-settling formulation that requires no shaking prior to administration. The vehicle behaves as a semisolid gel at rest, but shear-thins to a liquid when the bottle is squeezed, allowing it to flow and easily express as a drop. Upon mixing with tear fluid on the ocular surface, the vehicle converts to a liquid..$^{30}$ This avoids one of the major drawbacks of the ointment formulation, namely blurred vision. However, the LE gel formulation is thought to provide prolonged corneal and conjunctival contact time relative to the suspension formulation ${ }^{30}$ warranting continued vigilance with regard to potential safety ramifications, particularly with long-term use. Our study in post-PRK and post-LASIK patients included a sizable number of PRK eyes treated with LE gel for periods exceeding 60 and 90 days with little apparent effect on IOP. The two cases of IOP increase $\geq 10 \mathrm{mmHg}$ were noted at days 18 and 41, respectively, with higher frequency of use, and the IOP elevation returned to baseline with decreased frequency of administration in the case where follow-up information was available.

Advancements in PRK equipment and technique such as higher-quality lasers, small flying-spot delivery systems, and larger ablation zones may help reduce the incidence of corneal haze, nonetheless it still remains a risk, particularly in cases with high myopia. ${ }^{41-44}$ The frequency of corneal haze following PRK in this study was low; $19.1 \%$ of PRK eyes were noted to have any instance of corneal haze, and only $1.4 \%$ of PRK eyes developed haze that was classified as moderate/severe. While this study was not designed to evaluate efficacy and corneal abnormalities were gathered as safety findings, the low rate of corneal haze observed in this population may be an indication of clinical benefit of LE gel in that regard as well. While there was no control group in our analysis to provide perspective, the frequency of haze reported was very similar to findings reported in the chart review study by Mifflin et $\mathrm{al}^{26}$ comparing the suspension formulation of LE and FML in PRK patients. The percentage of eyes in that study with any incidence of haze ranged from approximately $18 \%$ to $27 \%$ during the first 2 months of follow-up. Visual outcomes in the two treatment groups were excellent, with a small, but statistically significant difference in favor of LE for mean uncorrected distance visual acuity at 6 months $(P=0.013)$.

The main limitations of this study are the lack of a control group and the real-world, retrospective nature of the data collection, the latter of which contributed unavoidable consequences of missing data, most notably with regard to IOP follow-ups and details regarding the duration of LE gel treatment in some cases. Likewise, data gathering was limited primarily to objective findings such as IOP measurements and surgical outcomes; it was not possible to evaluate more subjective variables such as pain relief or patient satisfaction. The primary goal of this chart review was to characterize patterns of LE gel use in refractive surgery and assess the overall safety in these settings. Collection of safety data in this study, as in any retrospective chart review, was limited to information previously recorded during routine patient follow-up visits. As a result, it is possible that minor complaints may not have 
been noted, and patients may not have been questioned about certain AEs. However, it is presumed that any such events of clinical significance would have been recorded.

Finally, applanation tonometry was used to determine pre- and postrefractive IOP at all five clinical sites participating in this retrospective chart review. IOP measures were not corrected to account for the decreased central corneal thickness (CCT) either in the patient charts or in the analysis of cumulative IOP data from all five sites. This may also be a limitation. Applanation tonometry is based on the assumption that eyes have a uniform shape and CCT, and may therefore underestimate the real IOP in postrefractive eyes, particularly in postoperative eyes of moderate and highly myopic patients where changes in CCT are known to be greater. However, to date, no accepted IOP-adjustment formulas have been established specifically for applanation tonometry in postkeratorefractive eyes to account for the change in CCT. While dynamic contour tonometry has been suggested to be more accurate for IOP measurements in postrefractive surgery eyes, ${ }^{45,46}$ it is not widely available. As a precaution, we recommend any postkeratorefractive surgery patient with IOP increases of $\geq 5 \mathrm{mmHg}$ as measured with applanation tonometry be followed more closely, especially in patients with greater depths of laser ablation. Despite the limitation of applanation tonometry, it is noteworthy that in the current chart review, there was only a relatively small percentage of patients with IOP elevations $\geq 5 \mathrm{mmHg}$.

\section{Conclusion}

Based on the real-world experience captured in this chart review, LE gel appears to have a high level of safety and tolerability when used for the management of postoperative pain and inflammation following LASIK and PRK surgery. AEs were few and not unexpected given the nature of refractive surgery cases, and there were no unusual corneal findings or healing abnormalities. The only meaningful safety-related findings included two PRK eyes with moderate/severe corneal haze and three PRK eyes of two patients with a clinically significant IOP elevation. These data corroborate a growing body of research suggesting that LE, in gel, suspension, and ointment formulation and in a variety of ocular surgical settings, provides the clinical benefits desired from a topical corticosteroid, and with an optimized safety profile.

\section{Acknowledgments}

Data collection and analysis was performed by Churchill Outcomes Research (Maplewood, NJ, USA) and funded by Bausch + Lomb, Inc. (Rochester, NY, USA). Writing assistance was provided by Sandra Westra, PharmD of Churchill Communications (Maplewood, NJ, USA), funded by Bausch + Lomb, Inc. This study was funded by Bausch + Lomb, Inc., Rochester, NY, USA.

\section{Disclosure}

CL Salinger has served as an advisory board member and paid speaker for Bausch + Lomb, Inc. MA Jackson is a consultant for Bausch + Lomb, Inc. The other authors report no conflicts of interest in this work.

\section{References}

1. American Academy of Ophthalmology Refractive Management/ Intervention Panel. Preferred Practice Pattern ${ }^{\circledR}$ Guidelines. Refractive Errors and Refractive Surgery. San Francisco, CA: American Academy of Ophthalmology; 2013. Available from: www.aao.org/ppp. Accessed May 4, 2015.

2. Naroo SA, Charman WN. Changes in posterior corneal curvature after photorefractive keratectomy. J Cataract Refract Surg. 2000;26:872-878

3. Dupps WJ, Wilson SE. Biomechanics and wound healing in the cornea. Exp Eye Res. 2006;83:709-720.

4. Shortt AJ, Allan BD, Evans JR. Laser-assisted in-situ keratomileusis (LASIK) versus photorefractive keratectomy (PRK) for myopia. Cochrane Database Syst Rev. 2013;1:CD005135.

5. Loewenstein A, Lipshitz I, Varssano D, Lazar M. Complications of excimer laser photorefractive keratectomy for myopia. J Cataract Refract Surg. 1997;23:1174-1176.

6. Alio JL, Artola A, Claramonte PJ, Ayala MJ, Sanchez SP. Complications of photorefractive keratectomy for myopia: two year follow-up of 3000 cases. J Cataract Refract Surg. 1998;24:619-626.

7. Moller-Pederson T, Cavanagh HD, Petroll WM, Jester JV. Stromal wound healing explains refractive instability and haze development after photorefractive keratectomy: a 1-year confocal microscopic study. Ophthalmology. 2000;107:1235-1245.

8. Donnenfeld ED, O'Brien TP, Solomon R, Perry HD, Speaker MG, Wittpenn J. Infectious keratitis after photorefractive keratectomy. Ophthalmology. 2003;110:743-747.

9. Wroblewski KJ, Pasternak JF, Bower KS, et al. Infectious keratitis after photorefractive keratectomy in the United States army and navy. Ophthalmology. 2006;113:520-525.

10. de Rojas V, Llovet F, Martinez M, et al. Infectious keratitis in 18,651 laser surface ablation procedures. J Cataract Refract Surg. 2011; 37:1822-1831.

11. Vetrugno M, Maino A, Quaranta GM, Cardia L. The effect of early steroid treatment after PRK on clinical and refractive outcomes. Acta Ophthalmol Scand. 2001;79:23-27.

12. Baek SH, Chang JH, Choi SY, Kim WJ, Lee JH. The effect of topical corticosteroids on refractive outcome and corneal haze after photorefractive keratectomy. J Refract Surg. 1997;13:644-652.

13. Aras C, Ozdamar A, Aktunc R, Ercikan C. The effects of topical steroids on refractive outcome and corneal haze, thickness, and curvature after photorefractive keratectomy with a $6.0-\mathrm{mm}$ ablation diameter. Ophthalmic Surg Lasers. 1998;29:621-627.

14. O'Brart DP, Lohmann CP, Klonons G, et al. The effects of topical corticosteroids and plasmin inhibitors on refractive outcome, haze, and visual performance after photorefractive keratectomy. A prospective, randomized observer-masked study. Ophthalmology. 1994;101: $1565-1574$.

15. McGhee CN, Dean S, Danesh-Meyer H. Locally administered ocular corticosteroids: benefits and risks. Drug Saf. 2002;25:33-55.

16. Bodor N, Loftsson T, Wu WM. Metabolism, distribution, and transdermal permeation of a soft corticosteroid, loteprednol etabonate. Pharm Res. 1992;9:1275-1278. 
17. Druzgala P, Wu WM, Bodor N. Ocular absorption and distribution of loteprednol etabonate, a soft steroid, in rabbit eyes. Curr Eye Res. 1991;10:933-937.

18. Comstock TL, DeCory HH. Advances in corticosteroid therapy for ocular inflammation: loteprednol etabonate. Int J Inflam. 2012;2012:789623. doi: $10.1155 / 2012 / 789623$

19. Comstock TL, Paterno MR, Singh A, Erb T, Davis E. Safety and efficacy of loteprednol etabonate ophthalmic ointment $0.5 \%$ for the treatment of inflammation and pain following cataract surgery. Clin Ophthalmol. 2011;5:177-186.

20. Lane SS, Holland EJ. Loteprednol etabonate $0.5 \%$ versus prednisolone acetate $1.0 \%$ for the treatment of inflammation after cataract surgery. J Cataract Refract Surg. 2013;39:168-173.

21. The Loteprednol Etabonate Postoperative Study Group 2. A doublemasked, placebo-controlled evaluation of $0.5 \%$ loteprednol etabonate in the treatment of postoperative inflammation. Ophthalmology. 1998;105:1780-1786.

22. Zhang Q-S, Wang X, Wang Z-H, et al. Influence of lotemax eyedrops on intraocular pressure following excimer laser corneal refractive surgery. Chin J Exp Ophthalmol. 2013;31(6):551-554.

23. Li W-T, Li H, Wei J. Clinical study on the application of $5 \mathrm{~g} / \mathrm{L}$ loteprednol etabonate ophthalmic suspension after LASIK. Int J Ophthalmol. 2010;10(9):1792-1793.

24. Gao D-H, Li K-J, Lu H. Clinical observations on the effect of Lotemax on changes in intra-ocular pressure after LASEK [sic: LASIK]. Int $J$ Ophthalmol. 2010;10(9):806-807.

25. Wu J-S, Zhong X-W, Zhang X-X, et al. A randomized controlled study on the application of $0.5 \%$ loteprednol etabonate eye drops after LASIK surgery. Chin J Exp Ophthalmol. 2012;30(7):641-645.

26. Mifflin MD, Leishman LL, Christiansen SM, Sikder S, Hsu M, Moshirfar M. Use of loteprednol for routine prophylaxis after photorefractive keratectomy. Clin Ophthalmol. 2012;6:653-659.

27. Thanathanee O, Sriphon $\mathrm{P}$, Anutarapongpan $\mathrm{O}$, et al. A randomized controlled trial comparing dexamethasone with loteprednol etabonate on postoperative photorefractive keratectomy. J Ocular Pharmacol Ther. 2015;31:165-168.

28. Holland EJ, Djalilian AR, Sanderson JP. Attenuation of ocular hypertension with the use of topical loteprednol etabonate $0.5 \%$ in steroid responders after corneal transplantation. Cornea. 2009;28:1139-1143.

29. Bartlett JD, Horwitz B, Laibovitz R, Howes JF. Intraocular pressure response to loteprednol etabonate in known steroid responders. $\mathrm{J} \mathrm{Ocul}$ Pharmacol. 1993;9:157-165.

30. Coffey MJ, DeCory HH, Lane SS. Development of a non-settling gel formulation of $0.5 \%$ loteprednol etabonate for anti-inflammatory use as an ophthalmic drop. Clin Ophthalmol. 2013;7:299-312.

31. Rajpal RK, Roel L, Siou-Mermet R, Erb T. Efficacy and safety of loteprednol etabonate $0.5 \%$ gel in the treatment of ocular inflammation and pain after cataract surgery. J Cataract Refract Surg. 2013;39:158-167.

32. Fong R, Leitriz M, Siou-Mermet R, Erb T. Loteprednol etabonate gel $0.5 \%$ for postoperative pain and inflammation after cataract surgery: results of a multicenter trial. Clin Ophthalmol. 2012;6:1113-1124.

33. International Conference on Harmonisation of Technical Requirements for Registration of Pharmaceuticals for Human Use. ICH Harmonised Tripartite Guideline. Guideline for Good Clinical Practice E6(R1). June 1996. Available from: http://www.ich.org/products/guidelines/ efficacy/efficacy-single/article/good-clinical-practice.html. Accessed October 8, 2015.

Clinical Ophthalmology

\section{Publish your work in this journal}

Clinical Ophthalmology is an international, peer-reviewed journal covering all subspecialties within ophthalmology. Key topics include: Optometry; Visual science; Pharmacology and drug therapy in eye diseases; Basic Sciences; Primary and Secondary eye care; Patient Safety and Quality of Care Improvements. This journal is indexed on Submit your manuscript here: http://www.dovepress.com/clinical-ophthalmology-journal
34. Pleyer U, Ursell PG, Rama P. Intraocular pressure effects of common topical steroids for post-cataract inflammation: are they all the same? Ophthalmol Ther. 2013;2(2);55-72.

35. White EM, Macy JI, Bateman KM, Comstock TL. Comparison of the safety and efficacy of loteprednol etabonate $0.5 \%$ /tobramycin $0.3 \%$ with dexamethasone $0.1 \%$ /tobramycin $0.3 \%$ in the treatment of blepharokeratoconjunctivitis. Curr Med Res Opin. 2008;24:287-296.

36. Chen M, Gong L, Sun X, et al. A multicenter, randomized, parallelgroup, clinical trial comparing the safety and efficacy of loteprednol etabonate $0.5 \% /$ tobramycin $0.3 \%$ with dexamethasone $0.1 \%$ /tobramycin $0.3 \%$ in the treatment of Chinese patients with blepharokeratoconjunctivitis. Curr Med Res Opin. 2012;28:385-394.

37. Holland EJ, Bartlett JD, Paterno MR, Usner DW, Comstock TL. Effects of loteprednol/tobramycin versus dexamethasone/tobramycin on intraocular pressure in healthy volunteers. Cornea. 2008;27:50-55.

38. Novack GD, Howes J, Crockett S, Sherwood MB. Change in intraocular pressure during long-term use of loteprednol etabonate. J Glaucoma. $1998 ; 7 ; 266-269$

39. Loteprednol Etabonate US Uveitis Study Group. Controlled evaluation of loteprednol etabonate and prednisolone acetate in the treatment of acute anterior uveitis. Am J Ophthalmol. 1999;127:537-544.

40. Jung HH, Ji YS, Sung MS, Kim KK, Yoon KC. Long-term outcome of treatment with topical corticosteroids for severe dry eye associated with Sjogren's syndrome. Chonnam Med J. 2015;51:26-32.

41. Allan BD, Hassan H. Topography-guided transepithelial photorefractive keratectomy for irregular astigmatism using a $213 \mathrm{~nm}$ solid-state laser. J Cataract Refract Surg. 2013;39:97-104.

42. Hansen RS, Lyhne N, Grauslund J, Gronbech KT, Vestergaard AH. Four-year to seven-year outcomes of advanced surface ablation with excimer laser for high myopia. Graefes Arch Clin Exp Ophthalmol. 2015;253(7):1027-1033.

43. Dawson DG, Grossniklaus HE, McCarey BE, Edelhasuer HF. Biomechanical and wound healing characteristics of corneas after excimer laser keratorefractive surgery: is there a difference between advanced surface ablation and sub-Bowman's keratomileusis? J Refract Surg. 2008;24:S90-S96.

44. Siganos DS, Katsanevaki VJ, Pallikaris IG. Correlation of subepithelial haze and refractive regression 1 month after photorefractive keratectomy for myopia. J Refract Surg. 1999;15:338-342.

45. Sadigh AL, Fouladi RJ, Hashemi H, Beheshtnejad AH. A comparison between Goldmann applanation tonometry and dynamic contour tonometry after photorefractive keratectomy. Graefes Arch Clin Exp Ophthalmol. 2013;251:603-608.

46. Aristeidou AP, Labiris G, Katsanos A, Fanariotis M, Foudoulakis NC, Kozobolis VP. Comparison between Pascal dynamic contour tonometer and Goldmann applanation tonometer after different types of refractive surgery. Graefes Arch Clin Exp Ophthalmol. 2011;249(5):767-773.

\section{Dovepress}

PubMed Central and CAS, and is the official journal of The Society of Clinical Ophthalmology (SCO). The manuscript management system is completely online and includes a very quick and fair peer-review system, which is all easy to use. Visit http://www.dovepress.com/ testimonials.php to read real quotes from published authors. 